\title{
Dental care too expensive for many middle-income Canadians
}

$\mathrm{M}$ ore than a third of middleincome Canadians say they can't afford dental care, reports a team of researchers at the University of Toronto in Ontario. The problem is especially pronounced among seniors; they are keeping more teeth than previous generations and thus need more dental care, but face lower income and discontinued or reduced insurance coverage after they retire.

"Initially we always thought [not going to the dentist] was a low-income issue," says Carlos Quiñonez, one of the researchers of the study (PLoS One 2013;8:e57377). However, they soon noticed that middle-class Canadians who lack dental insurance at work were not getting dental care.

The study analyzes data from an array of Statistics Canada surveys from 1978-2009. In 2009, middle-income Canadians had a lower level of dental insurance coverage than low- or highincome Canadians, with only $48.7 \%$ covered. The percentage who perceived cost-barriers to dental care also rose from $12.6 \%$ of middle-income Canadians in 1996 to $34.1 \%$ in 2009 . The study also found that children from middle-income families had, on average, the most severe cavities.

Provinces and territories have, to an extent, reduced financial barriers to necessary care for children from lowincome families, although programs often only cover "necessary" dental work (which may exclude preventive care), and don't provide much aid to adults. But middle-income Canadians haven't been considered at risk before.

Companies are offering less comprehensive insurance benefits, more Canadians are self-employed and uninsured, and most seniors lose their benefits when they retire, says Canadian Dental Association President Peter Doig.

"It's a changing environment. As we solve issues in one area, they crop up in another," he says.

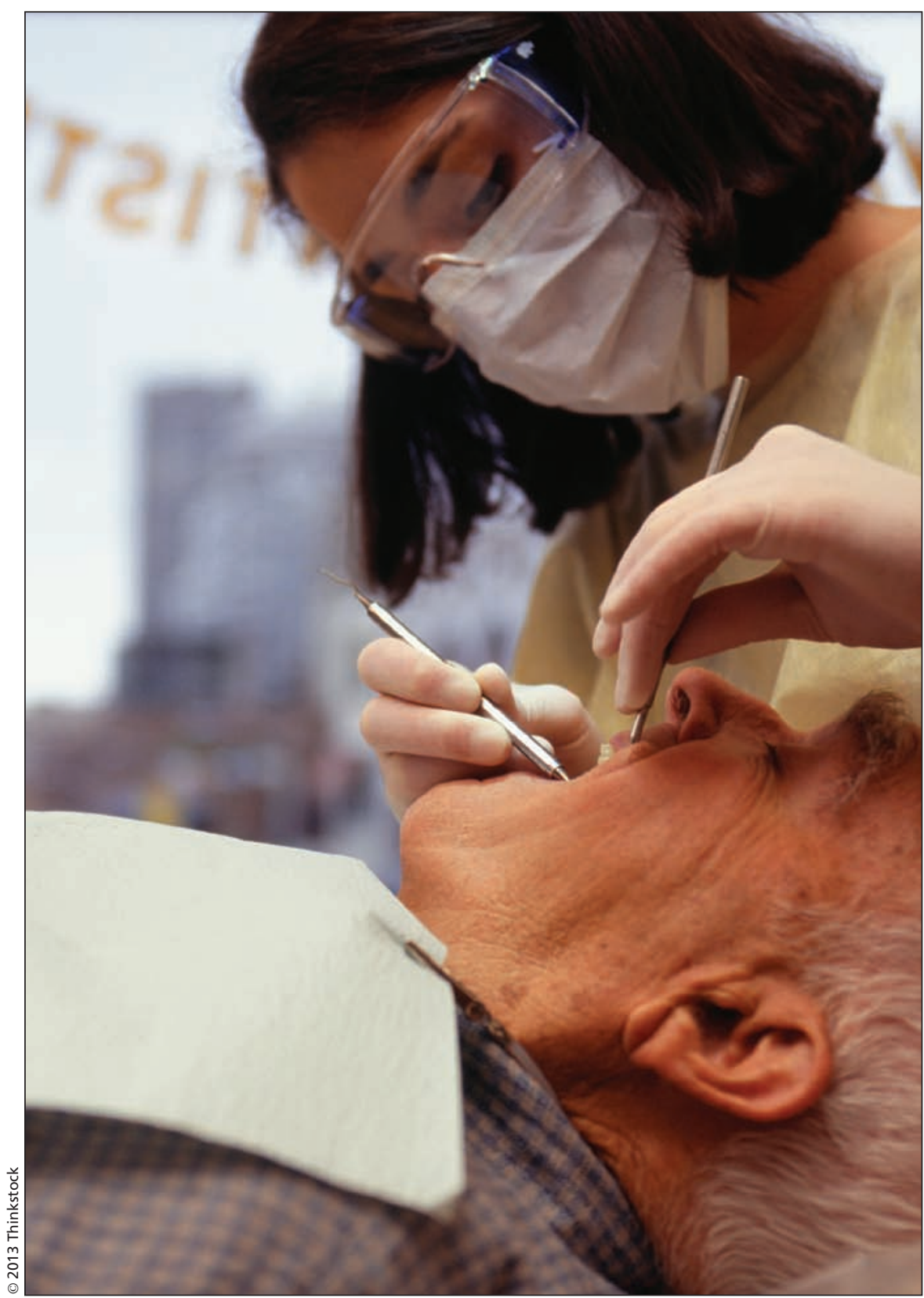

Financial barriers to dental care are growing for middle-income Canadians, and especially for seniors who lose their dental insurance when they retire.

Oral health has been marginalized in Canada's health care system as a personal responsibility, says Quiñonez, although oral health is important to overall well-being,

"One of the things I like to say when I speak to my medical colleagues is that if you were to unfold your gums you'd have a surface area the size of the volar surface of your forearm, essentially the inside surface from your wrist to your elbow," says 
Quiñonez. "If you had a severe infection that size on your arm, the health care system would move pretty damn quickly to fix you up if you went to go access care. But for some reason we just don't care when it comes to people's mouths."

In Canada, the adjusted cost of dental care increased by $730 \%$ between 1960 and 2008. Lower- and middleclass incomes have not paralleled this increase. Insured or not, this disparity is a problem, says Quiñonez.

"You could be insured, but if you make $\$ 15000$ dollars a year and your copayment is $\$ 100$, you may not be able to afford that."

The Canadian Dental Association is working to develop a national oral health strategy, Doig says, but it's difficult in a system he calls "fragmented."

"There's little coordination or plan- ning for the oral health care system," he says. "Access to care is something we have to be vigilant about. It's incumbent on us to plan how to deliver care to those areas that have gaps."

In addition to financial barriers, geography can also be a challenge, especially with fewer dentists in rural areas. - Catherine Cross, CMAJ

CMAJ 2013. DOI:10.1503/cmaj.109-4591 